\title{
Designing Real-Time: On How Events Affect Audiovisual Narrative
}

\author{
Marcus Bastos \\ PUC-SP, Brazil \\ info@contradiccoes.net
}

\begin{abstract}
Eventuality: designing real-time events presents projects developed by Marcus Bastos aiming to explore new formats of filming and editing, as a result of real-time technologies and their effects on audiovisual cultures. Design aspects will be highlighted, and contextualized by a broader discussion about concepts such as event, constructed situation, heterotopy, and others that describe momentarily occurences capable of shifting the functioning of an established system (be it a narrative, an algorithmic procedure, a form of ocuppying a stage or a specific region of a city).
\end{abstract}

Keywords: Event, constructed situation, hetorotopy, real-time, audiovisual, filming, editing.

\section{Introduction}

Contemporary society is increasingly defined by real-time events. Auto-publication systems and other platforms that allow instant commenting and sharing of content allow processes of communication in which collective updating, contextual framing and immediate reactions result in environments which are constantly evolving. Such environments behave according to custom settings, that make then specific to each and every user. User and location, among other variables, generate unique renderings of such systems. For that reason, they are not only accessed in real-time, but manifest that particular configuration only in that specific moment and context. This is applicable to every forms of networked mediations, though particularities of photos, sounds or videos means that specialized systems have proper characteristics according to their emphasis (be it hosting a collection of posts, sharing sets of images, or managing clips and playlists). Similarly to Heraclitus famous quote, it could be said that nobody access the same Facebook, Twitter, Youtube or Pininterest page twice.

The aim of this paper is to discuss how this real-time platforms are affecting audiovisual language, both in terms of filming and editing. Distribution could also be a topic, but it will not be highlithed at the moment, since the focus of this paper will be the design process of low-cost mobile units or editing interfaces, used mostly in live performances staged by means of improvising, or recreating dramaturgic situations. On the discussed projects, several aspects of real-time generations of images will be addressed, from generative procedures to modifications of given scripts or scores 
affected by live data or audience participation. Though technological aspects are crucial for this sort of experiment, they will not be taken as determinant. On a society overly defined by the devices and applications it uses, experimentation can be taken as a space to examine alternative perspectives, and sometimes they are also the result of performatic tactics of criticism, rather than technological deconstruction.

In terms of structure, the article will be divided in two distinct parts: a conceptual discussion of the concept of event, and others related with momentary occurrences; and a discussion of projects developed by the author exploring how new formats of filming and editing change audiovisual language. Although related, both parts are not an strict conversation. Some aspects of the conceptual discussion are broader, and address the cultural context in which the projects were created, rather than specific topics or issues developed. The projects are affected by the discussed context, but sometimes explore more specific questions, or isolated features of eventuality: Visible Cities uses existing webcam live feeds. Tosco Street View and related projects explore portable / moving filming units. fluxes deal with well-established vocabularies of generative visuals. Streaming Concert use voip to allow remote musicians to improvise onstage during a performed score.

\subsection{Events}

Events that occur in real time tend to be associated with immediacy. The word implies non-mediation, which might sound obvious but is worth mentioning, for the sake of the argument developed below. The difficulties of defining real-time will not be addressed on this article, since this would be material enough to generate a completely new one ${ }^{1}$. The existence of a shared, reasonably consensual, perception of a mutual and networked present that unfolds, as people interact with it, will be considered enough justification to discuss design possibilities to develop devices and interfaces that gather or edit data both on networks or wired cities. As Douglas Rushkoff puts it, in Present Shock, our "society has reoriented itself to the present moment. Everything is live, real time, and always-on. It's not a mere speeding up, however much our lifestyles and technologies have accelerated the rate at which we attemp to do things. It's more of a diminishment of anything that isn't happening right now - and the onslaught of everything that supposedly is"[1].

This perception happens nowadays as a result of an over-mediated environment, and despite the fact that ancient and newer forms of transmission equally mediate language in real-time. Nothing happens out of the bubble of present, so there is a

\footnotetext{
${ }^{1}$ Some of this problems were discussed in "Mundo em Tempo Real" (World in Real Time) and "iMaGeNSoNS: sincronias entre acontecimento e narrativa" (iMaGeSouNS: sincronicities between event and narrative", articles in which the author of this paper review ideas of theoriticians such as Bachelard, Bazin, Deleuze, and others, to discuss different concepts of time, showing how the continuous of past and present and its always updated relations result in the perception of passage of time, of an existing know and then, of a possible here and gone. Our relation with the context that surrounds us results of an interweaving of inputs and impulses that is already sophisticaded enough, without most recent technologies of mediation, in which the interval between action and response is closer to those of bodily interactions.
} 
paradox not to be disconsidered when we put emphasis on the real-timeness of current media processes. A not so obvious example of real-time mediation is an instrument, that amplifies sound waves and transmits them in form of vibrations in the air. A more explicitly mediated one is the satellite, that codifies audiovisual signals and transmits them (again, in form of aerial waves!) to a TV set. On both situations, the moment in which the mediated element is generated (either the sound or the TV image) almost coincides with the moment in which it is perceived by its recipient (either the listener of the sound or the TV watcher). So, what are the differences on recent processes of mediation, that results in a valorization of real-time phenomena and instantaneity?

Contemporary technologies are more explicitly perceived as real-time mediations because they depend on user agency. Simultaneity seems to be more easily identified in processes that happens by means of shared actions, where the passive position is nonexistent. That happens because the idea of presence is culturally associated with body participation: one is present when its body testifies an occurrence or interferes on it. And bodily actions are usually understood as distinct from device based actions: the body is perceived as immediate, devices are perceived as mediators. This understanding of presence as a bodily positioning endures, despite experiences such as that of a phone call. Since the $19^{\text {th }}$ century people interact from a distance. Yet, the several forms of telepresence known throughout history did not radically change the assumption of presence as a bodily feature, until very recently.

Mc Luhan states that "the age of anxiety and of electric media is also the age of the unconscious and of apathy /.../ With our central nervous system strategically numbed, the tasks of conscious awareness and order are transferred to the physical life of man, so that for the first time he has become aware of technology as an extension of his physical body. Apparently this could not have happened before the electric age gave us the means of instant, total field-awareness"[2]. It could be argued that this process was modified, as forms of agency appeared and shook people away of the passive role as consumers of language. Agency obliges people to leave their position of apathy. Touching a screen with a mouse (or directly, with the finger) blurs the distinction between mediator and mediated. Interfaced body and devices are allowed to perform joint actions, thus installing a shared present, a space of mutual existence. Of course, social and cultural processes are complex textures of numerous divergent, conflicting, discrepant elements. So, if recent political uprisings or people's habits of communication indicate a culture of action and participation, other aspects of current society points towards exclusion and lack of access. The reasonable conclusion would be that the present times are marked by tensions and conflicting models that dispute alternative futures, in a context of unclear outcomes.

The effect of augmented proximity produced by superimposing body, architecture and technology is enhanced by the experience of using interfaces that change, according to context and user profile. Environments that act in conformity with contextual parameters resemble organisms, in their capacity to adjust to situations. Technologies such as VOIP and social networks amplify the effect of a body that is, at the same time, remote and present. These mediated modes of presence reconfigure oral modes of communication, recursively mirroring through technological effects of sharing 
experiences in modes that were more akin to oral culture and its communal rituals of conversational exchanges. When touching a screen becomes as personal as talking with someone, people on the other side of the planet become more intimate than neighbors. With the aid of screens that transport (visual and sonore) fragments of a living room through high bandwidth connections, over there can become closer than right here.

Posting on interfaces in which people react and comment, seconds after content is available, produces an awareness of the passage of time, as if the present lasted more than the ephemerous moment one try to grasp, just to feel it vanished. On Cristals of Memory, Deleuze describes the bergsonian model of memory as a relationship of instants that shift away from the plane of experience, becoming virtual recollections of events[3]. Current networked technologies give materiality to this flux, in a distributed and cumulative format that display temporal succession in front of people's eyes. Social networks and intermittent webcam transmissions are equivalents of procedures tried in direct cinema or video art experiments, aiming to stress the passing of time (to quote the title of one of Bill Viola's well known pieces). The difference is that they are routinely, instead of exceptional. Dislocating to a different context Deleuze's affirmative, it would be possible to say that they present people to "something intolerable: their own routinicity"'[3].

On that context, events are perceived as occurrences that shift away from routine, producing difference on seas of similarity. When Edgar Morin organized the Cоттиnications edition focused on the return of the event, he was probably searching ways of thinking about a world affected by the disruptive unfoldings of May 68, undeniably one of the most intense set of deviations and questionings of all sorts of routines in recent history ${ }^{2}$. According to Morin, in Le Retour de L'événement, the concept of event "a été chassé dans la mesure où il a été identifié a la singularité, la contingence, l'accident, l'irreductibilité, le vécu (nous interrogerons plus loins le sens de ce mot événement)"[4]. So an event can be associated with something that happened, unpredictably, on a certain moment, and is unlikely to repeat, at least on the exact configuration it once happened. Abraham Moles explains that events are "des types de variations perceptibles d'un environment qui n'ont pas été prévues par l'occupant du centre de cet environment"'[5].

The polysemic and open definition proposed by Morin is, partially, resulting of the fact that his article presents a volume dedicated to multidisciplinary approaches to the concept of event, from sociological to historical, psychoanalitical and cybernetic. But the concept of event, in itself, deals with actions of certain openness and ungraspability (as stated by Moles, and also by Atlan, on the same publication). It would be incongruent to attribute predictable behaviors to an event, at least from the perspective of the action or object which is affected by its occurrence. Nevertheless, algorithmic description of such occurrences can be assumed as atributes of a given system. They are even necessary, in cases in which a system is modeled with parameters enough to trigger such unpredictable actions.

\footnotetext{
${ }^{2}$ May 68 was known, in France, as l'évenement, or the event.
} 
The complexity of the situation that evolves towards certain event is a given, even if the event in itself turns out to be simple, punctual or subtle. This plasticity and openness makes the concept of event relevant to describe a lot of what happens on contemporary environments in which networks of different kinds interveawe and allow a multiplicity of connections (temporally and geographically synchronous and/or asynchronous). The velocity of communications through the internet and mobile networks foment a culture in which the majority of the world seems to be promptly available through the click of a mouse, or the swipe of a finger. On such context, remote actions seem to affect unrelated communities, collective arrangements seem to emerge without predictable patterns. The complexity of the system makes its occurrences ungraspable to its participants.

On this article, the concept of event will be mainly associated with an unusual, unexpected action or behavior, a happening that desestabilizes and redirects the functioning of a narrative. This particular understanding of the word is historically related to cybernetics, in which an event reorganizes the functioning of an algorithmic routine. In Du bruit comme principe d'auto-organisation, Henri Atlan states that "Un pas de plus dans cette direction était réalisé, lors de recherces formelles sur la logique de systémes auto-organisateurs, en attribuant aux organismes la propriété non seulement de résister au bruit de façon efficace, mais encore de l'utiliser jusqu'a transformer en facteur de organisation! /.../ Soit un système exposé a un certain nombre de réponses. Chaque sucession pertubation-résponse met le systemé dans un certain état. Parmi tous les états possibles, seuls certains sont acceptables du point de vue de la finalité (au moins aparante) du systemé, que peut être sa simple survie ou l'accomplissement d'une fonction"[6].

Designing narrative structures that are affected in real-time by events which will change it (a space modifying a stream of events) or that will build temporary spaces mixing worlds and narratives (a stream of events modifying a space) install transitory places. Such spaces mixes fiction and reality in complex ways. It is a game-like situation, in wich the city becomes scenario for movies that happen in real-time with participation of spectators, actors and devices, as they are simultaneously shaped by the real world features surrounding it. This space of interfacing of real and fictional, as well as collective and individual, suggests new narrative formats that can explore our contemporary will to constantly participate and react. Overlaying public and networked spaces as devices for narrative allow to design real-time events to propose unexpected formats, that confront an audience accostumed with social networking and immediate reactions.

\subsection{Visible Cities: Designing a Multi-screen Space Fed by Webcams That Intermitently Films Public Areas}

Created in 2009, with an award from Itaú Cultural Rumos Expanded Language program, Visible Cities is a web documentary and multi-screen installation. It was developed by the LAT-23 collective, which is composed of Denise Agassi, Marcus Bastos, Claudio Bueno and Nacho Durán. The online version generate automatic clips of 8 minutes, by randomly mixing pre-recorded and live footage from webcams organized 
in sets of pre-defined tags and listed on the project's database. The installation version fill a darkened room with 5 monitors that display the live cameras, organized according to a collection of tags periodically sorted. The premise is that intermittent images of a place result in a situation opposite to the one to be expected. The project proposes an exploration of the flipside of the event, by showing how cameras that continuously capture images of cities generate an excedent of repetitive and inocuos imagery. Also, the combination of images of similar situations in different places of the globe results in repetitions that reveal how cities share a lot of common architectural and situational structures.

As stated by Agassi, Bastos, Bueno and Durán, on the project presented to Itaú Cultural describing the conceptual proposal for the piece, "putting side by side different kinds of registers of the world, available online, highlights a universe of evident monotony". For that reason, Visible Cities "reveals a dialog with etnography, and its project of incorporating the dead times of recordings into documentary, as if by doing so it would be possible to neutralize the process of selecting a specific perspective, during the editing process. But there is also an evident provocation when it is clear that exhaustive and intermittent register reveals few about the captured world. Almost as if a totality of gazes suggested its flipside: an incapacity of seeing".
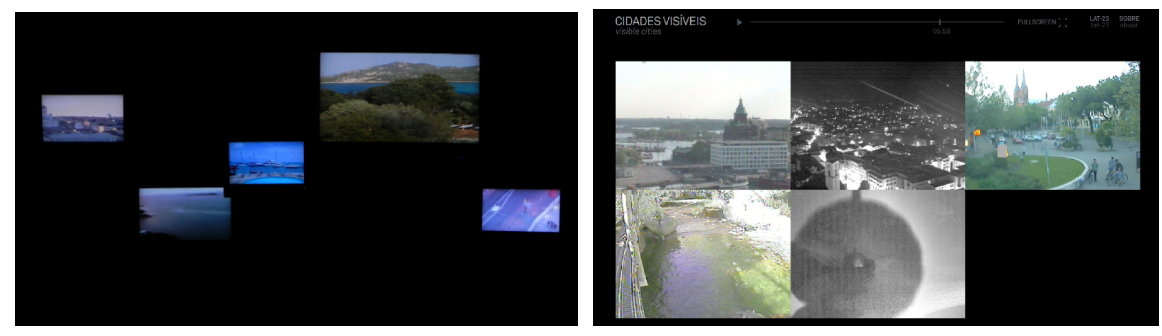

Fig. 1a. Visible Cities in the installation version exhibited at Itaú Cultural, in São Paulo: a realtime documentary using webcams feeds as ready-made footage, showing images of specific places around the globe, such as airports, parks, crossroads, harbours, etc. Fig. 1b. Visible Cities online interface: on the internet, the user can watch automatically generated 8 minutes clips, with images from pre-recorded and live webcams selected from the projects database.

Another aspect of Visible Cities is the automatic editing process, that create films that evolve in real-time from algorithmic decisions. Visible Cities aims to subvert the logic of filming and editing typical of cinema and video, with procedures of capturing online signal and tagging the resulting materials. The goal is to produce films in which live footage produce always unexpected results. It is impossible to anticipate what the online webcams embedded on the project's database will display. Also, by approximating then by a combination of tagging and spatial proximity, the piece stimulates arbitrary relationships between distant places. This kind of procedure relates to generative art, with the difference that the images are not generated, but edited through programming rules. Footage is already existing, but the spatial relations and order in which it will be displayed is generated every time the user clicks on the play button. 


\subsection{Tosco Street View: Designing Low-Tech Units for Filming Cities, as a Device for Real-Time Documentary}

Created in 2011, with a commission from SESC, Tosco Street View is a portable filming unit that explores precariousness as a strategy to deviate from the ambition of exhaustive landscape reconstruction associated with technologies used to capture images from places, and recreate them three-dimensionally. Collecting data of all kinds to generate visualizations based on 3-D models shows that one aspect of contemporary society resembles the paradoxical dream of creating the most complete possible map of a place, described by Borges on his short story Exactitude of Science. A map that ironically, when finally resembles the territory it represents, is rendered useless. Referring to such a map is similar to wandering through the areas it represent, since its extension does not allow any sort of generalization of inference about what is mapped. Our times are experiencing an obsession with organization of large data sets that can be compared to this quixotesce procedure of excessive detailment. It seems to be a reaction to an uncontrollable overload of information, as well as a shift in capacity of representation, as a result of the appearance of devices that read pieces of information that are not perceptible by bodily instruments, as well as images of unprecedented resolution exhibited on screens of previously unimagined proportions. The outcomes, it seems, points towards ungraspabilities not so different from the fictional borgean exactitude.
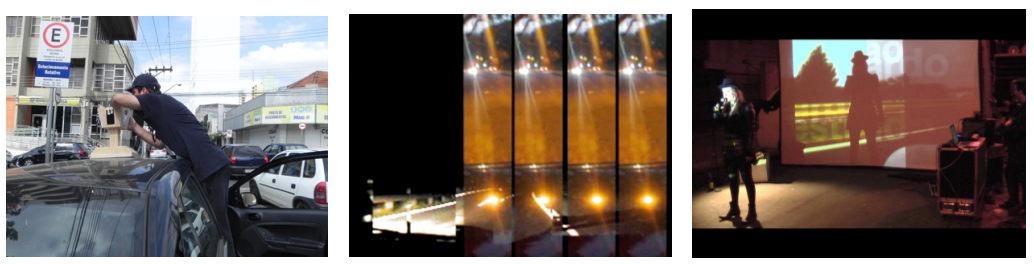

Fig. 2a. Preparing Tosco Street View to film in Piracicaba, during the SESC Circuit of Arts. This was the first version of the car, in which 3 cell phones and a tablet were used to capture images of cities throughout the state of São Paulo. Fig. 2b. 2c.The resulting material was used in she, lonely, thinks of that, a performance in which an actress would play the role of a woman who hits the road after being fired in a unexpected phone call, and revisits memories of her past through images and events occurring in the cities through which she passes.

The premise that structures Tosco Street View is that precarious and shattered images have their own share of informational insight, and that the ironic gesture of filming a city with a car that barely holds 4 low-res devices on its roof is, in itself, a statement that puts people to think about the times they live in. Unlike evangelists of resolution, a number of filmmakers and audiovisual artists have repeatly defended precarious images as sources of their poetics. In she, lonely, thinks of that, the first piece created with images filmed with the Tosco Street View, this fragmentation is explored as a feature. The scenes of the car driving through cities were edited in stripes, both of the four cameras in simultaneous views, or one camera repeteaded 4 times, to strengthen similarities and discontinuities between the different perspectives of the shots. 
She, lonely, thinks of that also research other aspects of eventuality, by means of an open narrative that adjusts to its context. The performance is created from a set of existing scenes, that are altered in two ways: it includes footage of the city where it will happen; the actress that plays the role of the main character interacts with the audience, and the generated situations dictates how the story will evolve. A live camera is used to include details of such interaction on the live mix, during the presentation. Also, elements of previous performances are included as new possibilities in future renderings of the project.

On its 2.0 version, the car uses streaming technologies and a feedback monitor to improve its presence on public space. Created to generate temporary TV stations aiming to provoke debates about local specific issues, the new version of the car benefits from low cost of portable tripods and existing apps to transmit video footage in real time, to upgrade into a more sophisticated unit, that allows scene selection and immediate transmition of the filmed materials. But this is not the most important unfolding of the project. Based on previous experience, this new version of Tosco Street View aim to foster more direct participation of audiences, as it films, and direct exchange of materials. The goal is to generate sound and video collections to produce real-time narratives about specific regions, mixing fictional and documentary elements.
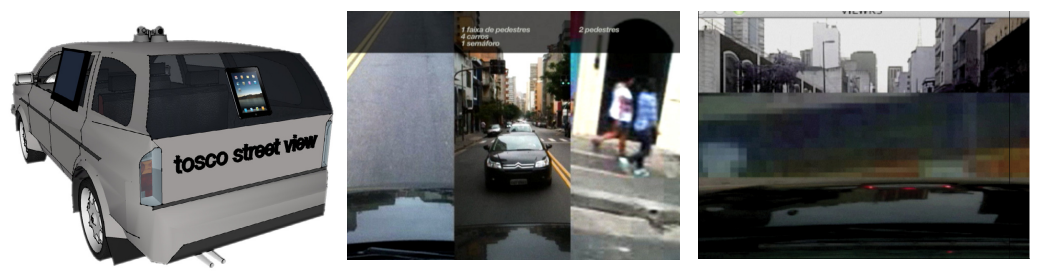

Fig. 3a. 3-D project for the 2.0 version of Tosco Street View, including streaming technologies, a feedback monitor and an iPad that allow people to record testimonies to be mixed with the material captured by the roof cameras. Fig. 3b. Perspectives is a short film created with the Tosco Street View for the Videoguerilha Festival; subtitles highlight details of scenes, showing how the automatic mode of footage production, resulting from the fact that its driver does not have control of the filmed angles, can result in interesting surprises and flagrants of different aspects of urban life. Fig. 3c. Remap was also produced for the Videoguerilha Festival; data records of latitude, longitude and altitude of the cars trajectory while filming is used to automatically change hue, luminosity and saturation of the resulting scenes.

\subsection{Fluxes: Designing Generative Ocupations of Space}

Launched in 2010, with a commission from Paço das Artes, fluxes is an audiovisual piece that explores the contrast between geometric and non-geometric patterns, in live improvisations based on 4 different themes. It was created by Telemusik, a collective composed by Marcus Bastos, Karina Montenegro and Dudu Tsuda (and guest participation of Richard Ribeiro). Embedded in the generative / visual music tradition, the piece nevertheless seeked spatial forms of displaying materials as a form to broaden a usually temporal based format. Also, fluxes seeks a tension between analogical and digital effects of recurrency and repetition, and how they can evolve to distention and increasing variations. 

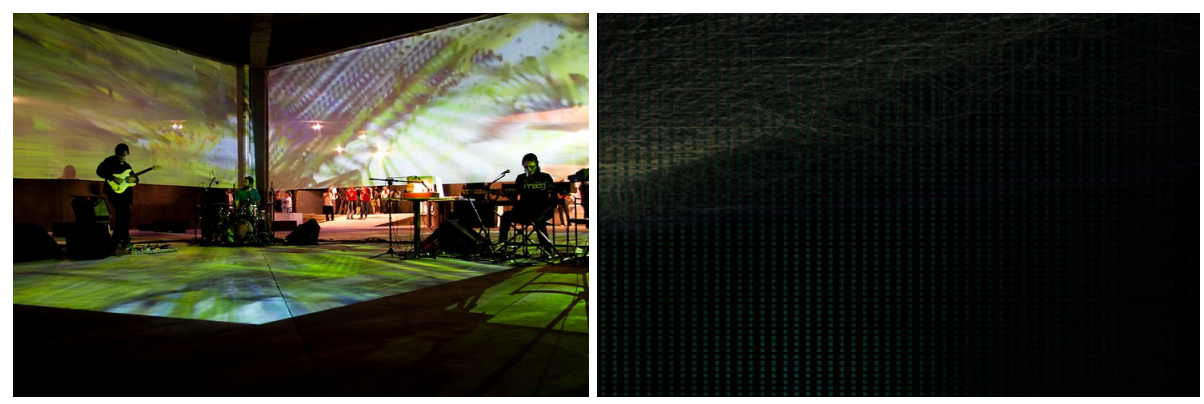

Fig. 4a. With two screen in a 90 degree angle and two reversed projections from ceiling to floor, fluxes is performed in a space that involves the musicians, video artists, and even those in the audience who decided to step inside the projected area while the piece was performed: analog effects and real-time shape generators were used to produce an abstract environment ranging from geometry to complexity. Fig $\mathbf{4 b}$. geometry/movement: screen capture of an improvisation with one of the visual patterns produced for fluxes.

Fluxes mixes aspects of staged performances traditions and installation, crossing pop culture with experimental languages. Real-time frictions of abstract visual and improvised sound occupy a space that was designed to dissolve the distance of italian stage formats. Here, there are no external inputs affecting the structure of the piece. The overall format is reasonably determined by a score and a set up. Events are rather the result of the musicians and video artist decisions, and how they react to each other, than a result of unpredictable parameters.

\subsection{Streaming Concert: Designing Remote Ocupations of a Stage}

Presented in 2011, as a hommage to John Cage's centenial, Streaming Concert proposes live improvistions of 3 pieces by Cage, with musicians distributed around the Globe. The technological project developed for the piece combines voip and syphon to embed remote calls from musicians that stream their images and sound, to be included on the live mix. Streaming Concert highlights the fragmented geographies existing as the result of real-time technologies of connection. Space gains a very different meaning, when people can telepresently performance. Distant interactions are not new, they happen since the 1970s, with well-know projects such as Hole in Space. On the current stage of such technologies, a further step is the possibility of lively manipulating this real-time inputs, transforming then in instantaneous footage for improvisation and mixing. It is a significant change, that shows how liveness, to use Paul Auslander's term, seem to have reached a very potent peek, in a society already fostered by processes in which instantaneity and mutual agency are crucial. 

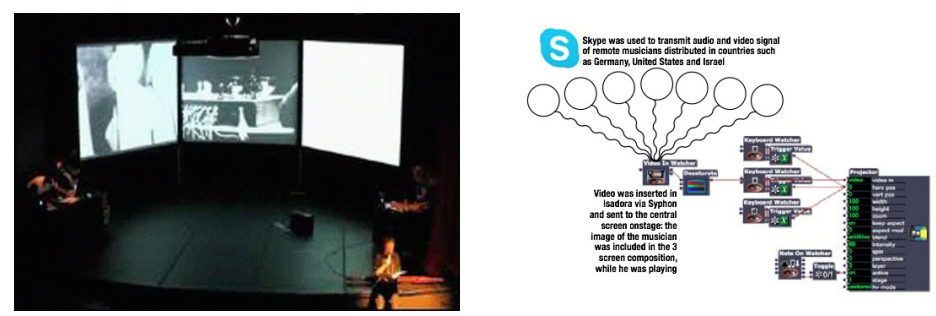

Fig. 5a. 3 screens were used to present live improvisation with images and footage related to Cage's imaginary (interviews, pictures, scores, etc). The central screen was used to insert live participations of remote musicians, that would send voip signal onstage according to a GMT based cue point. Fig 5b. Part of the Isadora project used to capture Skype audio and video and include it as a virtual webcam signal inside the composition used to perform Streaming Concert.

\section{References}

1. Rushkoff, D.: Present Shock - When Everything Happens Now. Penguin, New York (2013)

2. McLuhan, M.: Understanding Media. McGraw-Hill, London (1964)

3. Deleuze, G.: Cinema 2 - A imagem tempo. Brasiliense, São Paulo (2007)

4. Morin, E.: Le Retour de L'événement. Communications 18(18)

5. Moles, A.: Notes pour une typologies des événements. Communications 18(18)

6. Atlan, H.: Du bruit comme principe d'auto-organisation. Communications 18(18) 